\title{
Right to Sanitation: A Challenge in the Post Disaster Situations
}

\author{
Subhradipta Sarkar*
}

\section{Abstract}

Sanitation is an integral part of healthy living conditions. It is identified in various legal instruments in the form of right to adequate housing, health, water, etc. These rights are closely interlinked. The enforcement of these rights is dependent upon sanitation facilities. Sanitation remains one of the most neglected issues having serious implication on the lives and livelihoods of billions of people around the world. This paper contends that India being extremely disaster prone, sanitation is one of the crucial areas which require immediate attention in the aftermath of every disaster. Whether it is the Indian Ocean Tsunami (2004) or Aila (2009), the government failed to provide adequate sanitation facilities in most of the temporary shelters. The lack of inadequate drainage facilities, dysfunctional state of toilets, and absence of sufficient drinking water had resulted in unhygienic conditions. The paper cites various international instruments pertaining to the scope and importance of protection of right to water and sanitation during disasters. The Supreme Court of India has conceptualised 'right to sanitation' within the meaning of 'right to life' as guaranteed under our Constitution. Though sanitation has found mention in various domestic legislations including the Disaster Management Act, 2005, the scenario is far from encouraging. The paper identifies indifference of authorities towards the problem, unscientific construction of shelters and theory oriented

* Assistant Professor, ITM Law School, ITM University, Gurgaon; subhradipta.sarkar@gmail.com 
policies as causes responsible for the failure to address the issue of adequate sanitation. The paper offers certain suggestions to ensure a comprehensive policy safeguarding right to adequate sanitation in post disaster situations.

Keywords: Disaster Management; Human Rights; Sanitation; Supreme Court; Water

\section{Introduction}

Every year more than 200 million people, particularly from the developing countries, are affected by multiple types of disasters and the impact of such catastrophic events on water and sanitation systems is enormous. In Latin America and the Caribbean alone, such impact of natural disasters caused damages amounting to USD 650 million between 1994 and 2003. ${ }^{1}$ In 2010, the consequences of the massive earthquake in Haiti and devastating floods in Pakistan were equally disastrous. ${ }^{2}$ The United Nations estimates that about 2.5 billion people still lack access to improved sanitation and 1.2 billion practice open defecation. This has a profound negative impact on numerous human rights. Without sanitation facilities, one cannot enjoy the right to adequate housing. The impact of the lack of sanitation is also well documented. ${ }^{3}$ Yet, it

1 Pan American Health Organization et al., The Challenge in Disaster Reduction in Water and Sanitation Sector: Improving Quality of Life by Reducing Vulnerabilities v-vi (2006), available at http://esa.un.org/iys/ docs/san_lib_docs/DesafioDelAgua_Eng-intro.pdf (last visited Feb. 6, 2013).

2 International Federation of Red Cross and Red Crescent Societies, Annual Report 2010, 13-17 (2011), available at http://www.ifrc.org/ Global/Publications/annual-reports/IFRC-Annual-report-2010english.pdf.

${ }^{3}$ Human Rights Council, Report of the Independent Expert on the Issue of Human Rights Obligations Related to Access to Safe Drinking Water and Sanitation, Promotion and Protection of All Human Rights, Civil, Political, Economic, Social and Cultural Rights, Including the Right to Development, 4, A/HRC/12/24 (Jul. 1, 2009). 
remains one of the most neglected issues at the international and national levels.

Human excreta can become one of the foremost causes of disease if it is not safely disposed, out of human contact and away from water sources. In a post disaster situation, infrastructure generally takes a beating. Displaced people, overcrowded temporary shelters, inadequate water supplies and poor sanitation put lives at risk, and water, which is the supreme life sustaining element, becomes a source of major concern. Thus, disaster affected people become more vulnerable to ill health and death results from diseases due to inadequate sanitation, insufficient water supplies and poor hygiene. 4 Therefore, states are obligated to ensure everyone's access to a sufficient amount of safe drinking water for personal and domestic uses. These obligations require states to progressively ensure access to adequate sanitation and also protect the quality of drinking water supplies and resources. ${ }^{5}$

In the given circumstances, it is worthwhile to consider the case of India for two reasons. Firstly, the extreme vulnerability of the nation with regard to disasters. ${ }^{6}$ Among the 35 States and Union Territories in India, 27 are multi-disaster prone. ${ }^{7}$ Secondly, the sanitation situation in the country is in dire state. According to a recent assessment by United Nations, India will achieve the Millennium Development Goals ${ }^{8}$ on sanitation only by 2054 instead

4 Global Wash Cluster, The Human Right to Water and Sanitation in Emergency Situations 15 (2009), available at http:// www.actioncontrelafaim.org/sites/default/files/publications/ fichiers/acf_wash_promotion_final.pdf (last visited Feb. 6, 2013).

${ }^{5}$ See United Nations Humans Rights et al., Right to Water, Fact Sheet No. 35, 3, available at http://www.ohchr.org/Documents/Publications/ FactSheet35en.pdf (last visited Feb. 6, 2013).

6 National Disaster Management Division, Ministry of Home Affairs, Disaster Management in India - A Status Report 3 (2004).

7 See generally Second ADMIN. REFORMS COMMISSION (ARC), GOV'T OF INDIA (GoI), Crisis Management: From Despair to Hope $123^{\text {rd }}$ Report (2006).

8 The Millennium Development Goals are eight international development goals that all 193 United Nations member states and at least 23 
of 2015.9 The report further states that in spite of the fact that India has already achieved impressive results on water supply, 626 million people in the country defecate in the open, accounting for 60 per cent of the world's total open defecations. ${ }^{10}$

In such a situation, it is pertinent to explore for answers both for humanitarian reasons and from a right based perspective. The paper endeavours to give crucial inputs for formulation of a legal regime in the realm of disaster management which would link right to sanitation with other rights, e.g. right to water, life, shelter, etc. This would assist the state in setting appropriate standards for safeguarding people's right to sanitation, particularly in disaster situation. Hence, it becomes imperative to take a look into the international standards regarding disaster management and international human rights instruments. The paper also examines plethora of laws and policies in India which bear direct and indirect inferences to sanitation and allied areas. The objective of this paper is to assimilate the national and international norms in building a robust legal framework.

\section{Right to Sanitation: A Conceptual Discourse}

There is no clear definition of sanitation developed within the United Nations system. Different organisations have used varying definitions. ${ }^{11}$ So far as a normative definition of right to sanitation is concerned, the International Year of Sanitation (hereinafter referred to as "IYS") 2008 provided the much needed impetus. On the occasion of the launching of the IYS, it was declared that:

international organizations have agreed to achieve by the year 2015. MDG 7, Target 7c, calls on countries to halve, by 2015, the proportion of people without sustainable access to safe drinking-water and basic sanitation.

9 Aarti Dhar,, India will achieve sanitation goals only by 2054, THE HINDU, Mar. 27, 2012, available at http://www.thehindu.com/ news/ national/ article3250852.ece.

${ }^{10} \mathrm{Id}$.

11 World Health Organisation and United Nations Children's Fund, Joint Monitoring Programme for Water Supply and Sanitation (1981-1990), available at http://www.wssinfo.org/definitions-methods/introduction/. 
"Everyone, and that means all people in the world, has the right to a healthy life and a life with dignity. In other words: everyone has the right to sanitation." Taking this opportunity and on the occasion of the 16th Session of the Commission on Sustainable Development (May 2008), a group of nongovernmental organisations and international organizations made a first attempt at defining the right to sanitation in terms of human rights. In their first draft, the right to sanitation was defined as: "the entitlement of everyone to the safe collection, transport, treatment, disposal or reuse of human excreta and wastewater from personal and domestic uses, with associated hygiene promotion."12

Therefore, sanitation is a legal entitlement, and for realisation of the right, "sanitation shall be:

i. Safe: Sanitation must effectively prevent human, animal and insect contact with excreta.

ii. Physically accessible: Toilets must be, if not inside, then certainly in the immediate vicinity of all the users in a locality available for use at all times of the day or night, along with associated services such as removal of waste water and sewerage or latrine exhaustion.

iii. Affordable: Access to sanitation, including maintenance, must be affordable.

iv. Culturally sensitive: The construction and design of latrines should be culturally appropriate.

v. Sanitation should be non discriminatory and provided to vulnerable and marginalised groups.

vi. All people have the right to participate in decision making processes that may affect their access to sanitation and must be given full and equal access to information concerning sanitation.

vii. In terms of accountability, people who are denied their right to sanitation should have access to effective judicial or other

${ }^{12}$ Global Wash Cluster, supra note 4 at 50. 
appropriate remedies, regulatory agencies or human rights commissions." 13

The right to sanitation has its roots in and almost inseparable from right to water. Now it is common to refer to this right as right to water and sanitation. The connection between water and sanitation is clear; without proper sanitation, human excreta contaminate drinking water sources, affecting water quality and leading to disastrous health consequences. Water is further linked to sanitation because waterborne sewerage systems are common in many parts of the world. ${ }^{14}$

Interestingly, right to water has not been explicitly recognised as a self standing human right in international treaties. International human rights law entails specific obligations related to access to safe drinking water. In 2002, the UN Committee for Economic, Social and Cultural Rights (hereinafter referred to as "CESCR") adopted General Comment 15, which asserts that, "The human right to water is indispensable for leading a healthy life in human dignity. It is a prerequisite to the realisation of all other human rights." 15

While opinions may differ on whether to recognise sanitation as a distinct right, the independent expert on the issue of human rights obligations related to access to safe drinking water and sanitation asserts that there are clear human rights obligations related to sanitation because it is inextricably linked to, and indispensable for, the realization of many other human rights. Various international human rights instruments have included the rights to an adequate standard of living, adequate housing, health, education, water, work, life, physical security, etc. as various integral components of

13 See generally Centre on Housing Rights and Evictions, Water Aid, Swiss Agency for Development and Cooperation \& U.N. -HABITAT, Sanitation: A Human Rights Imperative 18-22 (Geneva 2008), available at http:/ / www.unhabitat.org/pmss/getElectronicVersion.aspx?nr=2927\&al $\mathrm{t}=1$.

14 U.N. Human Rights Council, supra note 3 at 33.

15 Committee on Economic, Social and Cultural Rights, Comment No. 15: The Right to Water, I 1, E/C.12/2002/11 (Jan. 20, 2003). 
sanitation. ${ }^{16}$ After vociferous debates for more than 15 years, eventually in 2010, the UN General Assembly has formally recognised the right to safe and clean drinking water and sanitation as a human right which is essential for the full enjoyment of life and all human rights. ${ }^{17}$ At the South Asian level, the Delhi Declaration (2008) which is the consequence of the $3^{\text {rd }}$ South Asian Conference on Sanitation has also held that access to sanitation and safe drinking water is a 'basic right'. 18

\section{Right to Sanitation under International Human Rights Treaties: India's Obligations}

It is pertinent to identify the provisions having ramifications on the right to sanitation under various international human rights treaties, particularly to which India is a party and analyse their scope. ${ }^{19}$ Various international human rights treaties including the International Covenant on Economic, Social and Cultural Rights (hereinafter referred to as "ICESCR") 1966, the Convention on the Elimination of All Forms of Discrimination Against Women (hereinafter referred to as "CEDAW") 1979, and the Convention on the Rights of the Child (hereinafter referred to as "CRC") 1989 have ushered the way for entailing obligations in relation to access to safe drinking water and sanitation. There is no disagreement over the fact that sanitation is yet to be recognised as a standalone right in the core human rights treaties; yet the right may be either derived from various provisions of these treaties or explicitly referred in conjunction with other rights. These international human rights treaties require the states to ensure access to

16 U.N. Human Rights Council, supra note 3.

17 The human right to water and sanitation, G.A. Res. 64/292, A/ RES/ 64/292 (Aug. 3, 2010).

18 The Delhi Declaration, The South Asian Conference on Sanitation (Nov. 2008), available at http://www.wateraid.org/ documents/ plugin_documents/delhi_declaration_sacosan_2008.pdf.

19 General comments provide an authoritative interpretation by an expert body on provisions under various international covenants, including the ICESCR. 
sanitation to its people. Needless to say, these human rights standards are general in nature and cover disaster situations as well. In March 2008, the UN Human Rights Council (hereinafter referred to as "UNHRC") adopted a resolution which emphasises that international human rights law, including the ICESCR, CEDAW and CRC involve such obligations in relation to access to sanitation. ${ }^{20}$

Considering the profound impact that the lack of sanitation has on an individual's quality of life, sanitation has frequently been understood to be indispensable for achieving an adequate standard of living. Article 11(1) of the ICESCR provides for "the right of everyone to an adequate standard of living for himself and his family, including adequate food, clothing and housing, and to the continuous improvement of living conditions." While this Article does not include sanitation explicitly, General Comment No. 15 of the CESCR clarifies that "the use of the word 'including' indicates that this catalogue of rights was not intended to be exhaustive." 21 It is therefore sound to conclude that the right to an adequate standard of living recognised under Article 11(1) of the ICESCR includes the right to sanitation, exactly like the rights to food, clothing and housing. ${ }^{22}$

The CESCR further notes that ensuring everyone "access to adequate sanitation is not only fundamental for human dignity and privacy, but is one of the principal mechanisms for protecting the quality of drinking water supplies and resources ... States parties have an obligation to progressively extend safe sanitation services, particularly to rural and deprived urban areas, taking into account the needs of women and children." 23

20 See generally Human Rights Council Res. 7/L.16, Human rights and access to safe drinking water and sanitation, A/HRC/7/L.16 (Mar. 20, 2008).

${ }^{21}$ Committee on Economic, Social and Cultural Rights, supra note 15 at 9 3.

${ }^{22}$ Centre on Housing Rights and Evictions, supra note 13 at $11-12$.

${ }^{23}$ Committee on Economic, Social and Cultural Rights, supra note 15 at 9 29. 
In addition, Article 27(1) of the CRC recognises the right of every child to an adequate standard of living. This has consistently been interpreted as encompassing access to clean drinking water and latrines by the Committee on the Rights of the Child, which is the treaty body in charge of monitoring and interpreting the CRC. ${ }^{24}$

Given the implication of sanitation on health, the CESCR in its General Comment No. 14 on the right to the highest attainable standard of health, underlined the fact that the drafting history of the ICESCR and the wording of its Article 12 (1) ${ }^{25}$ acknowledged that the right to health extended to the underlying determinants of health, including access to safe and potable water and adequate sanitation. ${ }^{26}$ The right attains greater importance in providing disaster relief and humanitarian assistance in times of emergency. ${ }^{27}$

It is significant to mention that in Chameli Singh $v$. State of Uttar Pradesh, ${ }^{28}$ the Supreme Court of India has expounded its own concept of a shelter. The Court observed:

"Right to shelter ... includes adequate living space, safe and decent structure, clean and decent surroundings, sufficient light, pure air and water, electricity, sanitation and other civic amenities like roads etc. so as to have easy

24 See generally Committee on the Rights of the Child: Kazakhstan, Concluding Observations, I 55 - 56, CRC/C/KAZ/CO/3 (2007); Committee on the Rights of the Child: Ethiopia, Concluding Observations, I 59 - 60, CRC/C/ETH/CO/3 (2006).

${ }^{25}$ International Covenant for Economic, Social and Cultural Rights art. 12. I 1, GA res. 2200A (XXI), 21 UN GAOR Supp. (No. 16), UN Doc. A/6316, at 49 (1966), available at http://www2.ohchr.org/english/ law/ pdf/cescr.pdf (the States Parties to the present Covenant recognize the right of everyone to the enjoyment of the highest attainable standard of physical and mental health).

26 United Nations Humans Rights, supra note 5 at $5-6$.

27 Committee on Economic, Social and Cultural Rights, Comment No. 14: The right to the highest attainable standard of health, I 16, 40, 65 E/C.12/2000/4 (Aug. 11, 2000).

${ }^{28}$ A.I.R. 1996 S.C. 1051. 
access to his daily avocation ... Right to shelter when used as an essential requisite to the right to live should be deemed to have been guaranteed as a fundamental right."

States are legally bound under international law to comply with international human rights treaties that they have ratified. Incidentally, India has ratified the ICESCR, CEDAW and CRC. International treaties are not self executing in case of India. For the successful implementation of international laws in the domestic legal system, they have to be transformed in to domestic law enacted by the Parliament as envisaged under Article 253 of the Constitution of India. Nevertheless, the Supreme Court has made commendable efforts in respecting the provisions of the international instruments. The Supreme Court in the case of Vishaka v. State of Rajasthan ${ }^{29}$ observed that the applicability of the principles of international law thereof may have to be read, if need be, into the domestic jurisprudence. The court also summed up the implications of international law through the following words:

"Any international convention not inconsistent with the fundamental rights and in harmony with its spirit must be read into these provisions to enlarge the meaning and content thereof, to promote the object of the constitutional guarantee. This is implicit from Art.51(c) ${ }^{30}$ and the enabling power of Parliament to enact laws for implementing the international conventions and norms by virtue of Art.253 with Entry $14^{31}$ of the Union List in the Seventh Schedule of the Constitution." 32

${ }^{29}$ A.I.R. 1997 S.C. 3011.

30 CONSTITUTION OF INDIA art. 51("Promotion of international peace and security. - The State shall endeavour to . . . (c) foster respect for international law and treaty obligations in the dealings of organized peoples with one another.").

31 Entering into treaties and agreements and implementation of treaties and agreements with foreign countries and implementing of treaties, agreements and conventions with foreign countries.

32 Vishaka v. State of Rajasthan, A.I.R. 1997 S.C. 3011 at $q 7$. 
In October 2010, the UN Human Rights Council (hereinafter referred to as "UNHRC") affirmed that the human right to safe drinking water and sanitation is derived from the right to an adequate standard of living and inextricably related to the right to the highest attainable standards of physical and mental health, as well as the right to life and human dignity. ${ }^{33}$ Thus, it is a part of existing international law which is legally binding upon states. The UNHRC calls upon the states to develop appropriate tools and mechanisms to achieve the full realisation of this right in unserved and underserved areas. ${ }^{34}$

The message of UNHRC read in conjunction with the observations of the Supreme Court regarding the implications of the international law, makes it mandatory for our government to abide by the provisions of those international human rights instruments and take all appropriate measures to prevent any violation of the right to water and sanitation.

\section{International Humanitarian Standards Relating to Sanitation}

There are numerous standards dealing with emergency preparedness and response to natural disasters. The author has taken a few into consideration. These instruments do not address the issue of water and sanitation per se; they deal with disaster management. There is another important distinction between these instruments and the human rights treaties mentioned in the previous section. While the treaties are binding upon those countries that have ratified the same, these instruments are as such non binding in nature. Nevertheless, they are essential in setting the standards for emergency preparedness and response.

To begin with, the Inter Agency Standing Committee Operational Guidelines on the Protection of Persons in Situations of Natural

${ }^{33}$ Human Rights Council Res. 15/9, Human rights and access to safe drinking water and sanitation, \3, A/HRC/RES/15/9 (Oct. 6, 2010). ${ }^{34} \mathrm{Id}$. at 98. 
Disasters ${ }^{35}$ promotes and facilitates a rights based approach to humanitarian assistance activities, including the provision of safe drinking water and sanitation. Thus, the victims become individual rights holders who can claim rights from particular duty bearers rather than simply being passive beneficiaries and recipients of charity. ${ }^{36}$ The guidelines emphasise that the actors involved in the humanitarian services must ensure that in temporary camps and collective shelters as well as permanent relocation sites, there are adequate water and sanitation facilities. This includes water pumps, toilets and bathing facilities accessible particularly to women, persons with disabilities and old persons. ${ }^{37}$

Another important standard for humanitarian assistance is the Sphere Project launched in 1997 by a group of humanitarian organisations and the Red Cross and Red Crescent movements. Sphere adopts a similar definition of sanitation to General Comment No. 15. It consists of a Humanitarian Charter based on various principles and provisions including those of international humanitarian law, international human rights law, refugee law and Minimum Standards in Disaster Response. 38

The minimum standards regarding water, sanitation and hygiene promotion are an expression of rights embodied in the Humanitarian Charter. It includes promotion of hygiene, water supply, disposal of excreta, vector control, solid waste management and drainage. The main objective of water supply and sanitation programmes during disasters is to reduce the transmission of faeco oral diseases and exposure to disease bearing vectors through the

35 See generally Inter-Agency Standing Committee, IASC Operational Guidelines on the Protection of Persons in Situations of Natural Disasters: The Brookings - Bern Project on Internal Displacement 2 (Jan., 2011), available at ochanet.unocha.org/p/Documents/Operational\%20Guidelines.pdf.

$36 \mathrm{Id}$.

${ }^{37} \mathrm{Id}$. at 33 .

38 THE SPHERE PROJECT, HUMANITARIAN CHARTER AND MiNiMUM STANDARDS IN DISASTER RESPONSE 5 (2004), available at http://www.bb.undp.org/uploads/file/pdfs/crisis/Sphere $\% 20$ handboo k.pdf. 
promotion of good hygiene practices, the provision of safe drinking water and the reduction of environmental health risks, by establishing conditions that allow people to live with good health, dignity, comfort and security. ${ }^{39}$

Unlike few countries like South Africa, Panama, Zambia and Uruguay, the Constitution of India or any national legislation does not expressly provide right to sanitation as a legal right. However, Article 47 of the Constitution dealing with Directive Principles of State Policy states that it shall be the primary duty of the state to raise the standard of living of its people and the improvement of public health. This objective cannot be achieved without due emphasis being given to better sanitation facilities. On many occasions, disasters have deleterious impact on water and sanitation. Therefore, needless to say, such situations demand more attention.

Under the federal scheme of the Constitution, states have the primary responsibility to enact law on water supply 40 as well as public health and sanitation. ${ }^{41}$ Such provisions make it abundantly clear that the responsibility to ensure adequate and safe supply of water, maintain cleanliness and taking care of health and hygiene of the people lies with the state governments. Furthermore, while conferring constitutional status to the panchayats and municipalities through the 73rd and 74th constitutional amendments in 1992, the Constitution has conferred powers on the state legislatures to vest the local authorities with power to implement schemes relating to water supply and sanitation. The panchayats are empowered under Article 243G of the Constitution read in conjunction with Entry 11 of Schedule XI to ensure safe drinking water, while the municipalities are empowered under Article $243 \mathrm{~W}$ read in conjunction with Entry 6 of Schedule XII to implement schemes relating to public health and sanitation.

\footnotetext{
${ }^{39} \mathrm{Id}$. at 56 .

${ }^{40}$ CONSTITUTION OF INDIA art. 246(3), Sch. VII, List II, Entry 17.

${ }^{41}$ CONSTITUTION OF INDIA art. 246(3), Sch. VII, List II, Entry 6.
} 
However, there are no mandatory provisions for devolution of powers on these local bodies. It has been left to the discretion of the states. The constitutional devolution of any new powers on the panchayats and municipalities cannot be presumed. The lists under the Eleventh and Twelfth Schedules of the Constitution are advisory in nature. States have the discretion in conferring powers to local authorities. This implies that the powers of local bodies to manage water are subsidiary to those of the states and the central government. ${ }^{42}$ Nevertheless, such devolution is absolutely necessary to empower the local authorities so that they could carry out sanitation work effectively enhancing the preparedness of the communities. All state laws regarding water and sanitation shall compulsorily have disaster management component to make them more useful.

\section{Judicial Interpretation of Right to Sanitation}

Though the Constitution has not enumerated the right to water and sanitation, the Supreme Court of India and various High Courts of the country, through judicial activism, have evolved this right. The Supreme Court in Virender Gaur v. State of Haryana ${ }^{43}$ has held that right to life under Article 21 inter alia encompasses sanitation within its ambit without which it would be impossible to live with human dignity.

The importance of right to sanitation was emphatically proclaimed through a landmark judgment of the Supreme Court in the case of Municipal Council, Ratlam v. Vardichand. ${ }^{44}$ The key question that had to be addressed by the court was whether by affirmative action a court can compel a statutory body to carry out its duty to the community by constructing sanitation facilities on a time bound basis.

42 See Environmental Law Research Society (ELRS), A Primer on Water Law and Policy in India 8 (Jan. 2012), available at http:// elrs.in/ content/ draft_primer.pdf.

43 (1995) 2 S.C.C. 5.

${ }^{44}$ A.I.R. 1980 S.C. 1622. 
While replying in affirmative, the Supreme Court referred to Section 123 of the Madhya Pradesh Municipalities Act, 1961 and held:

"We are sure that the state government will make available by way of loans or grants sufficient financial aid to the Ratlam Municipality to enable it to fulfill its obligations under this order. The state will realize that Article 47 of the Constitution makes it a paramount principle of governance that steps are taken 'for the improvement of public health as amongst its primary duties'. The municipality also will slim its budget on low priority items and elitist projects to use the savings on sanitation and public health." 45

In L.K. Kootwal v. State of Rajasthan, ${ }^{46}$ while responding to the writ petition regarding acute sanitation problem which is hazardous to the life of the citizens of Jaipur, the High Court of Rajasthan held that Jaipur Municipality had violated residents' right to life by failing to implement adequate sanitation measures. The ambit of the obligations under Article 51A (g) of the Constitution which imposes a fundamental duty on every citizen "to protect and improve the natural environment..." was a prime concern in this case. The court directed the municipality to remove the dirt, filth etc. within a period of six months and clean the entire Jaipur city.

Our judiciary has generally shown indifference towards the victims of natural disasters. ${ }^{47}$ A greater degree of judicial activism is required in this arena. If circumstances demand, suo motu intervention of the court would be a welcome relief for the victims of disasters. As the courts have already held right to sanitation as a part of life under Article 21 of the Constitution, it is now imperative on the state to enact laws to ensure that the right is available to all the victims in the post disaster situation in a non discriminatory

${ }^{45}$ Municipal Council, Ratlam v. Shri Vardhichand \& Ors., A.I.R 1980 S.C. 1622.

${ }^{46}$ A.I.R. 1988 Raj. 2.

47 Subhradipta Sarkar and Archana Sarma, Disaster Management: A Black Hole in Indian Judicial System, 26(6) LEGAL NEWS AND VIEWS 14 - 20 (Jun., 2012). 
manner, especially taking into consideration the special needs of the vulnerable groups.

\section{Legal and Policy Framework Relating to Right to Sanitation}

In the absence of statutory law, the central government has come up with several schemes in the rural sector, of which the most important is the Total Sanitation Campaign (Sampoorna Svachta Andolan). It is a demand driven and community led programme that ensures sanitation facilities in rural areas with a broader goal to eradicate the practice of open defecation. In addition to the existing provisions under the Total Sanitation Campaign, the Rural Sanitation and Hygiene Strategy (2011-2020) provides a framework to realize the vision of Nirmal Bharat, an environment that is clean, healthy and contributes to the economic and social well being of all rural citizens. Besides, National Rural Drinking Water Programme links drinking water with other schemes such as sanitation, health policy, education and the Mahatma Gandhi National Rural Employment Guarantee Scheme. ${ }^{48}$ Despite the fact that rural India often faces severe crisis of water and sanitation during multiple disasters, yet none of the rural schemes mention water and sanitation in a disaster situation.

The legal framework in the urban areas is relatively complex. The National Urban Sanitation Policy 2008 deals with the challenges of urban sanitation. It insists that that those cities which are vulnerable to natural disasters, special measures for sanitation must be explicitly incorporated in their disaster preparedness and mitigation plan. If such a plan does not exist, the city sanitation task force must lay out the steps to be taken for the city to cope with such disasters. ${ }^{49}$ Municipal legislations are the primary source of the powers, functions and duties of urban local bodies relating to water supply. Almost all municipal Acts contain more or less similar provisions regarding water. In some states, laws have been

48 See generally Environmental Law Research Society, supra note 42 at 13 15.

49 See generally Ministry of Urban Development, National Urban Sanitation Policy 17 (2008). 
adopted to constitute a separate authority with full control over all aspects of water supply and sanitation. Tamil Nadu Water Supply and Drainage Board Act, 1970, Uttar Pradesh Water Supply and Sewerage Act, 1975 are a few of them. ${ }^{50}$

After a perusal of these laws, the author opines that there are no provisions to deal with the issue of sanitation in the context of disaster management. There are no provisions relating to disaster preparedness so far as sanitation is concerned. In some cases, e.g. Delhi, different areas of the same city may be governed by different laws. ${ }^{51}$ Such a chaotic legal regime is one of the major reasons for a sorry state of sanitation in the country. Situation gets worse when there are disasters. Sanitation conditions were seriously inadequate particularly in the urban slum areas in the aftermath of Orissa super cyclone in 1999. The municipality sewerage system was extensively damaged. In normal times, nearly 90 per cent had access to safe water, but only $4 \%$ had sanitation. There was no doubt about the fact that the situation worsened further after the super cyclone. 52

It may be pointed out that the National Urban Sanitation Policy envisions National Award Scheme for Sanitation for Indian Cities to promote sanitation in urban areas of the country and recognize excellent performance in this area. However, there is no monetary incentive for the same. ${ }^{33}$ Apart from awards, sponsorship to participate in national events, trainings, and exchange and learning visits to other locations, incentives may also be given in form of disbursement of more development funds to the concerned authorities. Such steps will encourage better performance and enhance preparedness for any impending disaster. It is surprising that the disaster management policy does not have any such provision either.

${ }^{50}$ Environmental Law Research Society, supra note 42 at 29.

${ }^{51}$ Id. at 19 .

52 World Health Organisation, Super Cyclone in Orissa, India, available at http://www.foodrelief.org/articles/super-cyclone-in-orissa-india.html (last visited Jan. 27, 2013).

${ }^{53}$ See generally Ministry of Urban Development; supra note 49 at $34-37$. 


\section{Legal Regime Relating to Disaster Management}

The principal legislation regarding disaster management in the country is the Disaster Management Act, 2005. There is mention about sanitation in the Act. The Act casts responsibility on the National and State Disaster Management Authorities (hereinafter referred to as "NDMA and "SDMA") to recommend guidelines for the minimum standards of relief to be provided to persons affected by disaster, which shall inter alia include the minimum requirements to be provided in the relief camps in relation to shelter, food, drinking water, medical cover and sanitation. ${ }^{54}$ The concern has been reflected in NDMA Guidelines on Management of Tsunamis with regard to emergency relief and setting up of relief camps. 55

The local authorities are usually the first responders; hence, they play a very significant and varied role in managing natural disasters. The Act empowers the District Disaster Management Authority (hereinafter referred to as "DDMA") in numerous ways including identifying buildings and places which could, in the event of any disaster, be used as relief centres or camps and make arrangements for water supply and sanitation in such buildings or places. ${ }^{56}$ Similar steps have been recommended in guidelines on management of floods.

Recently, the government has formulated National Policy on Disaster Management (2009). The policy has urged all central ministries, state governments, district authorities and other stakeholders to prepare standard operating procedure (hereinafter referred to as "SOP") in consonance with the national and state plans. The SOPs will respond to various important activities including provision for drinking water, sanitation and

${ }^{54}$ Disaster Management Act, No. 53 of 2005 (2005) § 12, § 19.

55 National Disaster Management Authority (NDMA), National Disaster Management Guidelines: Management of Tsunamis \ 6.3.1, ๆ 6.9.2 (NDMA 2010).

${ }^{56}$ Disaster Management Act, 2005 § 30(xxiv). 
management of relief camps. ${ }^{57}$ It acknowledges that the post disaster management of health, sanitation and hygiene services is crucial. Hence, medical response has to be quick and effective and there shall be constant monitoring to prevent an outbreak of epidemics. 58

\section{Conclusion}

It has been demonstrated throughout the paper that right to water and sanitation has direct relation with right to adequate housing or health. Yet, the fundamental problem in disaster management in India is that we give more importance to housing, with sanitation taking a backseat. This is inherently a flawed approach. Instead, if we can show greater concern towards water and sanitation, we would be better able to safeguard other rights of the disaster victims. The Human Rights Commission in India must take note of the situation and do the needful.

${ }^{57}$ National Disaster Management Authority, supra note 55 at 9 7.5.1.

${ }^{58} \mathrm{Id}$. at 9 7.9.1. 